\title{
The association of diabetes with COVID-19 disease severity: evidence from adjusted effect estimates
}

\author{
Xuan Liang ${ }^{1} \cdot$ Jie Xu ${ }^{1} \cdot$ Wenwei Xiao $^{1} \cdot$ Li Shi $^{1} \cdot$ Haiyan Yang ${ }^{1}$ (D) \\ Received: 5 August 2020 / Accepted: 4 November 2020 / Published online: 25 November 2020 \\ (C) Hellenic Endocrine Society 2020
}

To the Editor,

Diabetes, which is one of the leading causes of mortality and morbidity worldwide with increasing prevalence, is a wellknown risk factor for various infections, post-infection complications, and increased mortality secondary to infections [1]. Diabetes has now been shown to be among the most common medical conditions in patients who develop coronavirus disease 2019 (COVID-19) [2] and has been associated with higher mortality in patients with this disease [3]. Zheng et al. reported that diabetes is associated with an almost fourfold greater risk for severe disease and death in patients with COVID-19 (odds ratio $(\mathrm{OR})=3.68,95 \%$ confidence interval (CI) [2.68-5.03]; $P<0.001)$ [4]. However, although a significant association was observed between diabetes and disease severity (including severe and critical conditions and mortality) among COVID-19 patients based on the data of unadjusted effect estimates (hazard ratio (HR)) in the study by Cummings et al., this disappeared based on the data of the adjusted effect estimates [5], which suggest that several factors such as age, gender, and underlying diseases might modulate the relationship between diabetes and COVID-19 disease severity. Therefore, it was evident that the association between diabetes and severe COVID-19 disease needed to be investigated via a quantitative meta-analysis based on the data of adjusted effect estimates.

A systematic literature search was conducted for studies published from January 1, 2020, to July 25, 2020, in the PubMed, Chinese National Knowledge Infrastructure (CNKI), and Web of Science databases. According to the indices of the various databases, we used the search terms "coronavirus disease 2019," "2019-nCoV, SARS-CoV-2," "COVID-19," and "diabetes," and "diabetes mellitus." Only

Haiyan Yang

yhy@zzu.edu.cn

1 Department of Epidemiology, School of Public Health, Zhengzhou University, Zhengzhou 450001, China articles reporting adjusted effect estimates (adjusted OR or HR) for diabetes and severity of disease in COVID-19 patients were considered eligible. There was no restriction on country or location. All calculations were carried out with Stata 11.2 software. The pooled OR and pooled HR with their corresponding 95\% CI were applied to evaluate the risk of severity in diabetic patients with COVID-19. The choice of the appropriate effects model was based on the analysis results, as follows: the fixed effect model was used if $I^{2}$ was $<50 \%$ and the random-effects model was used if $I^{2}$ was $\geq 50 \%$ [6]. Sensitivity analysis was conducted to evaluate the robustness of the results. Publication bias among the included studies was assessed by employing Begg's funnel plot and Egger's test.

A total of 1057 studies were identified using the search algorithm. Twenty-three studies [5, 7-28], comprising a total of 22,359 patients, were considered to be eligible for inclusion (Table 1). The median age of the patients ranged from 44 to 71 years; 4407 (20\%) of them had diabetes. Among the 23 included articles, there were 19 retrospective studies and four prospective studies.

The forest plot of the association between diabetes and the severity of COVID-19 symptoms is shown in Fig. $1 \mathrm{a}$ and b. Diabetes was found to be associated with an increased risk of disease severity in COVID-19 patients on the basis of 14 studies reporting adjusted OR $(\mathrm{OR}=1.44,95 \%$ CI $[1.14$ 1.82], $I^{2}=58.2 \%$, random-effects model) (Fig. 1a) and nine studies reporting adjusted HR (HR $=1.37,95 \%$ CI [1.191.57]; $I^{2}=29.2 \%$, fixed-effects model) (Fig. 1b). In the 23 studies we included, only 11 studies reported both unadjusted and adjusted effect estimates (HR or OR) simultaneously. We calculated the pooled unadjusted and adjusted effect estimates (HR or OR) separately, and the pooled results based on unadjusted effect estimates showed that diabetes was associated with greater risk for disease severity in patients with COVID-19 compared to the pooled results based on adjusted effect estimates $\left(\mathrm{HR}_{\text {unadjusted }}=2.04(95 \% \mathrm{CI}: 1.30-3.19)\right.$ and $\mathrm{OR}_{\text {unadjusted }}=2.98(95 \% \mathrm{CI}: 1.75-5.05) ; \mathrm{HR}_{\text {adjusted }}=1.61$ (95\% CI: $1.28-2.04)$ and $\mathrm{OR}_{\text {adjusted }}=1.58$ (95\% CI: $1.07-$ 


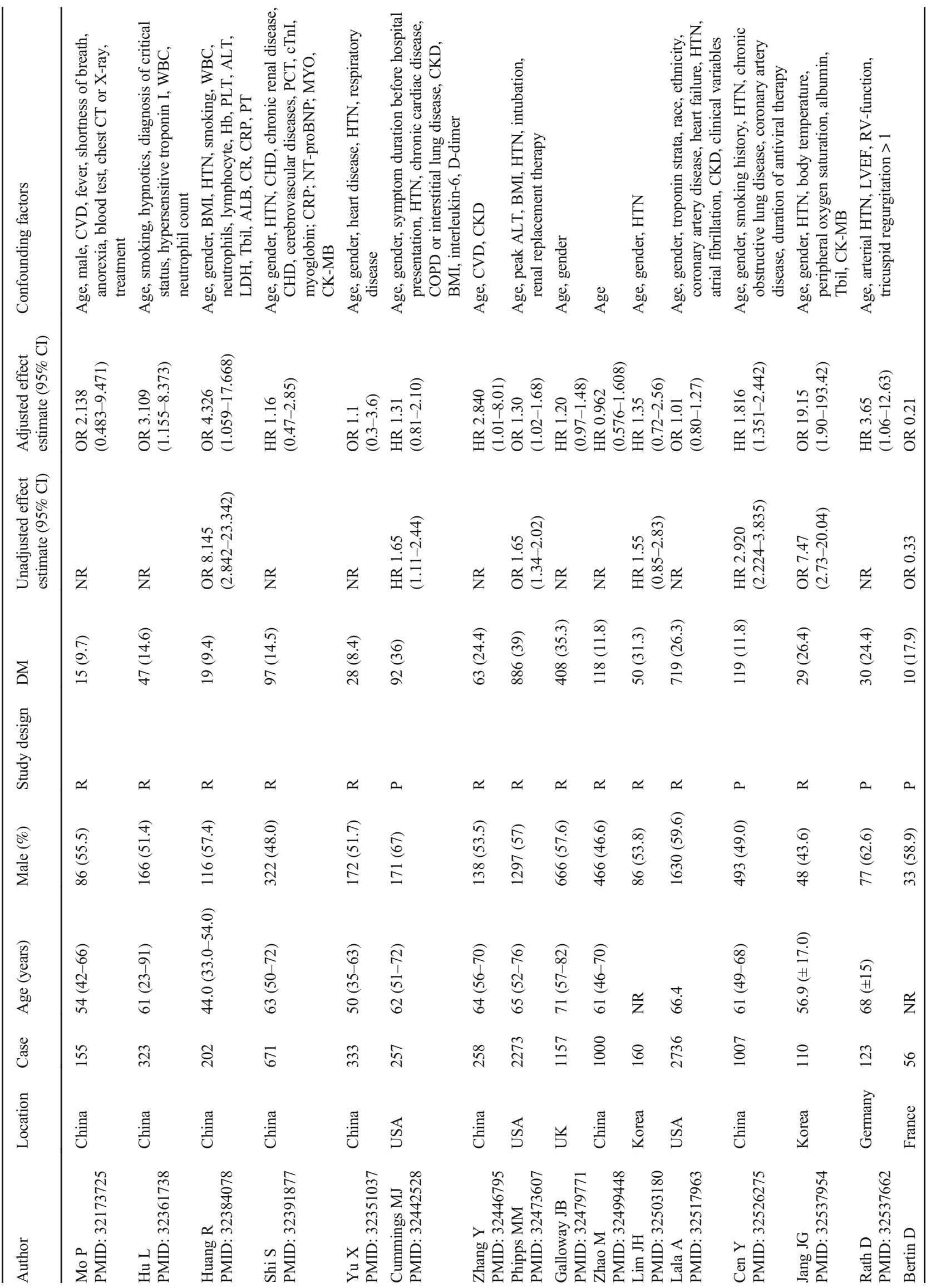




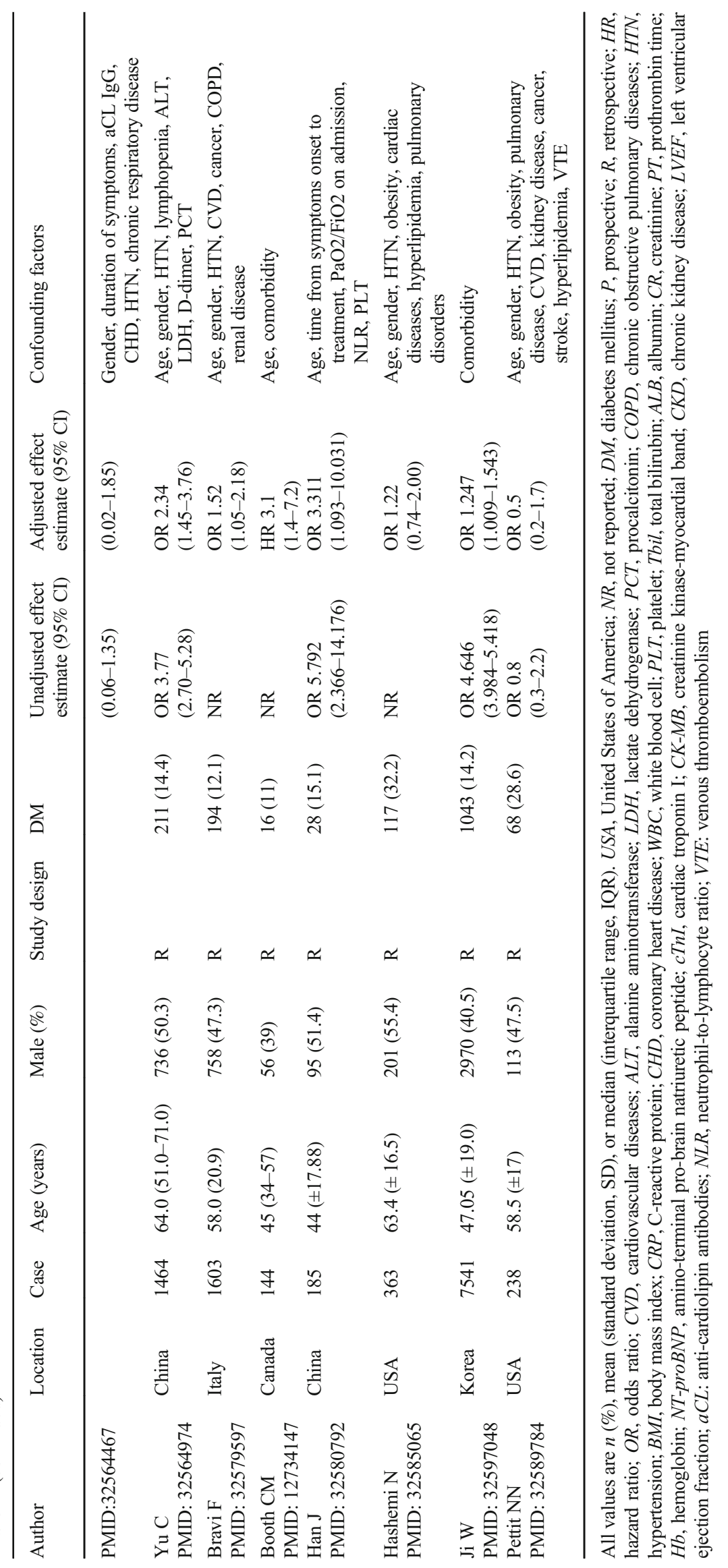


Fig. 1 The pooled odds ratio (OR) (a), hazard ratio (HR) (b), and their $95 \%$ confidence interval (CI) of the relationship between diabetes and the risk of disease severity in patients with COVID19. Sensitivity analysis for evaluating the relationship between diabetes and the risk of disease severity in patients with COVID-19 (c) a

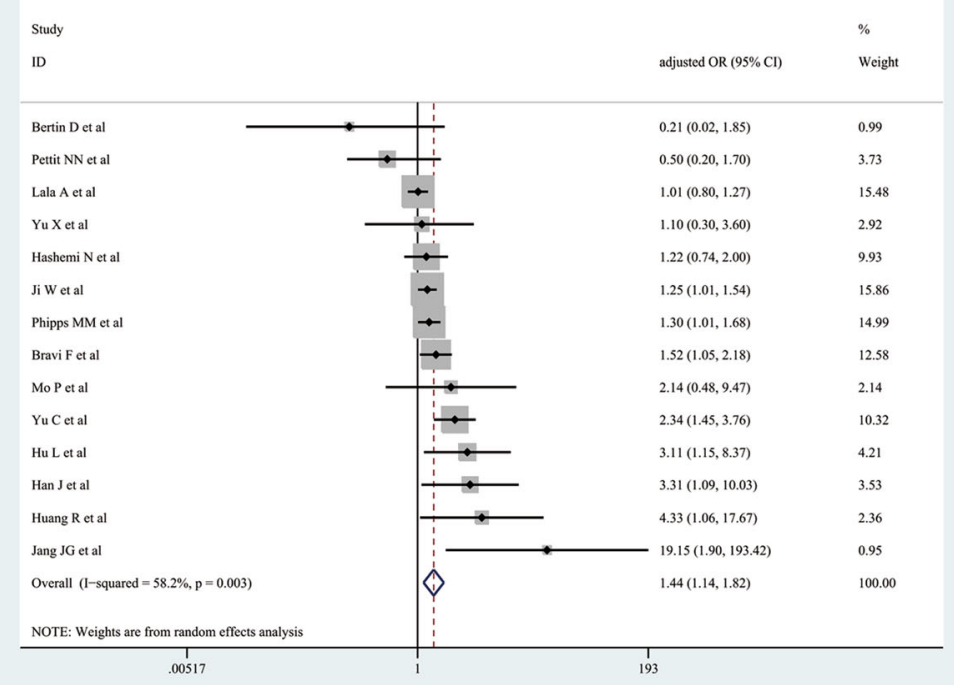

b

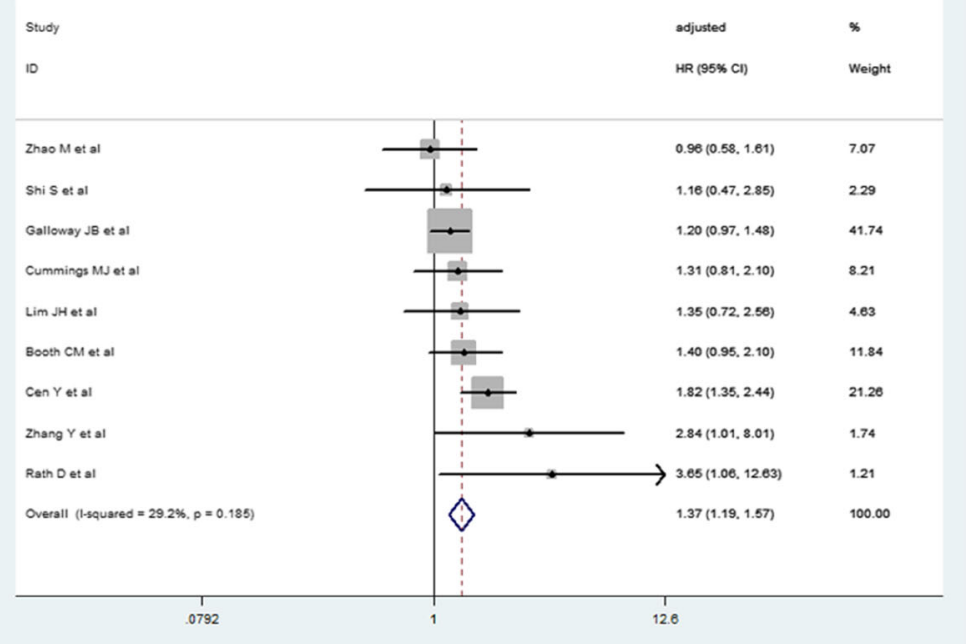

C

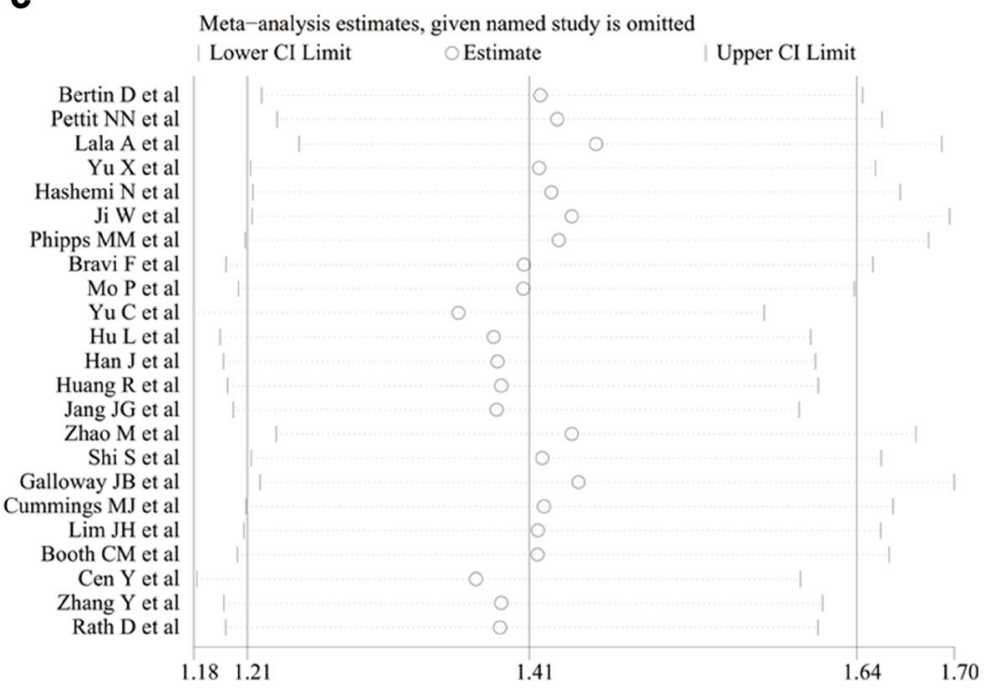


2.32), respectively) (Fig. S1). Sensitivity analysis indicated that our results were robust and stable (Fig. 1c). There was no significant publication bias, as determined by Begg's test $(P=0.224)$ and Egger's test $(P=0.065)$.

Although previous meta-analyses have demonstrated that diabetes was positively associated with an increased risk of severity and mortality in COVID-19 patients, these studies did not uniformly address the influences of several factors, including age, gender, and underlying diseases, on the results $[4$, 29-33]. Therefore, our present study investigated the relationship between diabetes and disease severity in COVID-19 patients based on adjusted effect estimates: the results demonstrated that diabetes was an independent predictor of COVID19 disease severity.

Some limitations should be considered in our study. Firstly, the definitions of severity of COVID-19 varied among the included studies. Secondly, the type of diabetes and whether it was with good or with poor glycemic control are also unknown. Because the selected studies did not adequately present data on the treatment of diabetes and blood glucose control, these could not be evaluated. Finally, all selected studies presented adjusted effect estimates, but the adjusted confounders among the studies were not completely consistent: for example, the number and kinds of adjusted confounders are different among the included studies.

In conclusion, our findings indicated that diabetes is an independent risk factor for predicting COVID-19 disease severity in these patients. These results clearly underscore the necessity to increase our focus in clinical practice on COVID19 patients with diabetes so as to prevent rapid deterioration of their condition.

Given the limited level of evidence, further well-designed studies with larger samples are needed to confirm our current results.

Supplementary Information The online version contains supplementary material available at https://doi.org/10.1007/s42000-020-00259-x.

Funding This study was supported by a grant from the National Natural Science Foundation of China (No. 81973105). The funder has no role in data collection and analysis, manuscript preparation, and decision to submission.

\section{Compliance with ethical standards}

Conflict of interest The authors declare that they have no conflicts of interest.

\section{References}

1. Frydrych LM, Bian G, O’Lone DE, Ward PA, Delano MJ (2018) Obesity and type 2 diabetes mellitus drive immune dysfunction, infection development, and sepsis mortality. J Leukoc Biol 104(3):525-534. https://doi.org/10.1002/JLB.5VMR0118-021RR
2. Palaiodimos L, Kokkinidis DG, Li W, Karamanis D, Ognibene J, Arora S, Southern WN, Mantzoros CS (2020) Severe obesity, increasing age and male sex are independently associated with worse in-hospital outcomes, and higher in-hospital mortality, in a cohort of patients with COVID-19 in the Bronx, New York. Metab Clin Exp 108:154262. https://doi.org/10.1016/j.metabol.2020.154262

3. Huang C, Wang Y, Li X, Ren L, Zhao J, Hu Y, Zhang L, Fan G, Xu J, Gu X, Cheng Z, Yu T, Xia J, Wei Y, Wu W, Xie X, Yin W, Li H, Liu M, Xiao Y, Gao H, Guo L, Xie J, Wang G, Jiang R, Gao Z, Jin Q, Wang J, Cao B (2020) Clinical features of patients infected with 2019 novel coronavirus in Wuhan, China. Lancet (London, England) 395(10223):497-506. https://doi.org/10.1016/s01406736(20)30183-5

4. Zheng Z, Peng F, Xu B, Zhao J, Liu H, Peng J, Li Q, Jiang C, Zhou Y, Liu S, Ye C, Zhang P, Xing Y, Guo H, Tang W (2020) Risk factors of critical \& mortal COVID-19 cases: a systematic literature review and meta-analysis. J Infect. https://doi.org/10.1016/j.jinf. 2020.04.021

5. Cummings MJ, Baldwin MR, Abrams D, Jacobson SD, Meyer BJ, Balough EM, Aaron JG, Claassen J, Rabbani LE, Hastie J, Hochman BR, Salazar-Schicchi J, Yip NH, Brodie D, O'Donnell MR (2020) Epidemiology, clinical course, and outcomes of critically ill adults with COVID-19 in New York City: a prospective cohort study. Lancet 395(10239):1763-1770. https://doi.org/10. 1016/s0140-6736(20)31189-2

6. Greenland S (1987) Quantitative methods in the review of epidemiologic literature. Epidemiol Rev 9:1-30. https://doi.org/10.1093/ oxfordjournals.epirev.a036298

7. Bertin D, Brodovitch A, Beziane A, Hug S, Bouamri A, Mege JL, Bardin N (2020) Anti-cardiolipin IgG autoantibodies are an independent risk factor of COVID-19 severity. Arthritis Rheum. https:// doi.org/10.1002/art.41409

8. Booth CM, Matukas LM, Tomlinson GA, Rachlis AR, Rose DB, Dwosh HA, Walmsley SL, Mazzulli T, Avendano M, Derkach P, Ephtimios IE, Kitai I, Mederski BD, Shadowitz SB, Gold WL, Hawryluck LA, Rea E, Chenkin JS, Cescon DW, Poutanen SM, Detsky AS (2003) Clinical features and short-term outcomes of 144 patients with SARS in the greater Toronto area. Jama 289(21): 2801-2809. https://doi.org/10.1001/jama.289.21.JOC30885

9. Bravi F, Flacco ME, Carradori T, Volta CA, Cosenza G, De Togni A, Acuti Martellucci C, Parruti G, Mantovani L, Manzoli L (2020) Predictors of severe or lethal COVID-19, including angiotensin converting enzyme inhibitors and angiotensin II receptor blockers, in a sample of infected Italian citizens. PLoS One 15(6):e0235248. https://doi.org/10.1371/journal.pone.0235248

10. Cen Y, Chen X, Shen Y, Zhang XH, Lei Y, Xu C, Jiang WR, Xu HT, Chen Y, Zhu J, Zhang LL, Liu YH (2020) Risk factors for disease progression in patients with mild to moderate coronavirus disease 2019-a multi-centre observational study. Clin Microbiol Infect. https://doi.org/10.1016/j.cmi.2020.05.041

11. Galloway JB, Norton S, Barker RD, Brookes A, Carey I, Clarke BD, Jina R, Reid C, Russell MD, Sneep R, Sugarman L, Williams S, Yates M, Teo J, Shah AM, Cantle F (2020) A clinical risk score to identify patients with COVID-19 at high risk of critical care admission or death: an observational cohort study. J Infect. https://doi.org/10.1016/j.jinf.2020.05.064

12. Han J, Shi LX, Xie Y, Zhang YJ, Huang SP, Li JG, Wang HR, Shao SF (2020) Analysis of factors affecting the prognosis of COVID-19 patients and viral shedding duration. Epidemiol Infect 148:e125. https://doi.org/10.1017/s0950268820001399

13. Hashemi N, Viveiros K, Redd WD, Zhou JC, McCarty TR, Bazarbashi AN, Hathorn KE, Wong D, Njie C, Shen L, Chan WW (2020) Impact of chronic liver disease on outcomes of hospitalized patients with COVID-19: a multicentre United States experience. Liver Int. https://doi.org/10.1111/liv.14583 
14. Hu L, Chen S, Fu Y, Gao Z, Long H, Wang JM, Ren HW, Zuo Y, Li H, Wang J, Xu QB, Yu WX, Liu J, Shao C, Hao JJ, Wang CZ, Ma Y, Wang Z, Yanagihara R, Deng Y (2020) Risk factors associated with clinical outcomes in 323 COVID-19 hospitalized patients in Wuhan, China. Clin Infect Dis. https://doi.org/10.1093/cid/ ciaa539

15. Huang R, Zhu L, Xue L, Liu L, Yan X, Wang J, Zhang B, Xu T, Ji F, Zhao Y, Cheng J, Wang Y, Shao H, Hong S, Cao Q, Li C, Zhao XA, Zou L, Sang D, Zhao H, Guan X, Chen X, Shan C, Xia J, Chen Y, Yan X, Wei J, Zhu C, Wu C (2020) Clinical findings of patients with coronavirus disease 2019 in Jiangsu province, China: a retrospective, multi-center study. PLoS Negl Trop Dis 14(5):e0008280. https://doi.org/10.1371/journal.pntd.0008280

16. Jang JG, Hur J, Choi EY, Hong KS, Lee W, Ahn JH (2020) Prognostic factors for severe coronavirus disease 2019 in Daegu, Korea. J Korean Med Sci 35(23):e209. https://doi.org/10.3346/ jkms.2020.35.e209

17. Ji W, Huh K, Kang M, Hong J, Bae GH, Lee R, Na Y, Choi H, Gong SY, Choi YH, Ko KP, Im JS, Jung J (2020) Effect of underlying comorbidities on the infection and severity of COVID-19 in Korea: a nationwide case-control study. J Korean Med Sci 35(25): e237. https://doi.org/10.3346/jkms.2020.35.e237

18. Lala A, Johnson KW, Januzzi JL, Russak AJ, Paranjpe I, Richter F, Zhao S, Somani S, Van Vleck T, Vaid A, Chaudhry F, De Freitas JK, Fayad ZA, Pinney SP, Levin M, Charney A, Bagiella E, Narula J, Glicksberg BS, Nadkarni G, Mancini DM, Fuster V, Mount Sinai Covid Informatics C (2020) Prevalence and impact of myocardial injury in patients hospitalized with COVID-19 infection. J Am Coll Cardiol. https://doi.org/10.1016/j.jacc.2020.06.007

19. Lim JH, Park SH, Jeon Y, Cho JH, Jung HY, Choi JY, Kim CD, Lee YH, Seo H, Lee J, Kwon KT, Kim SW, Chang HH, Kim YL (2020) Fatal outcomes of COVID-19 in patients with severe acute kidney injury. J Clin Med 9(6). https://doi.org/10.3390/ jcm9061718

20. Mo P, Xing Y, Xiao Y, Deng L, Zhao Q, Wang H, Xiong Y, Cheng Z, Gao S, Liang K, Luo M, Chen T, Song S, Ma Z, Chen X, Zheng R, Cao Q, Wang F, Zhang Y (2020) Clinical characteristics of refractory COVID-19 pneumonia in Wuhan, China. Clin Infect Dis. https://doi.org/10.1093/cid/ciaa270

21. Pettit NN, MacKenzie EL, Ridgway J, Pursell K, Ash D, Patel B, Pho MT (2020) Obesity is associated with increased risk for mortality among hospitalized patients with COVID-19. Obesity (Silver Spring, Md). https://doi.org/10.1002/oby.22941

22. Phipps MM, Barraza LH, LaSota ED, Sobieszczyk ME, Pereira MR, Zheng EX, Fox AN, Zucker J, Verna EC (2020) Acute liver injury in COVID-19: prevalence and association with clinical outcomes in a large US cohort. Hepatology. https://doi.org/10.1002/ hep. 31404

23. Rath D, Petersen-Uribe A, Avdiu A, Witzel K, Jaeger P, Zdanyte M, Heinzmann D, Tavlaki E, Muller K, Gawaz MP (2020) Impaired cardiac function is associated with mortality in patients with acute COVID-19 infection. Clin Res Cardiol. https://doi.org/ $10.1007 / \mathrm{s} 00392-020-01683-0$
24. Shi S, Qin M, Cai Y, Liu T, Shen B, Yang F, Cao S, Liu X, Xiang Y, Zhao Q, Huang H, Yang B, Huang C (2020) Characteristics and clinical significance of myocardial injury in patients with severe coronavirus disease 2019. Eur Heart J 41(22):2070-2079. https:// doi.org/10.1093/eurheartj/ehaa408

25. Yu C, Lei Q, Li W, Wang X, Liu W, Fan X, Li W (2020) Clinical characteristics, associated factors, and predicting COVID-19 mortality risk: a retrospective study in Wuhan, China. Am J Prev Med. https://doi.org/10.1016/j.amepre.2020.05.002

26. Yu X, Sun X, Cui P, Pan H, Lin S, Han R, Jiang C, Fang Q, Kong D, Zhu Y, Zheng Y, Gong X, Xiao W, Mao S, Jin B, Wu H, Fu C (2020) Epidemiological and clinical characteristics of 333 confirmed cases with coronavirus disease 2019 in Shanghai, China. Transbound Emerg Dis. https://doi.org/10.1111/tbed.13604

27. Zhang Y, Cui Y, Shen M, Zhang J, Liu B, Dai M, Chen L, Han D, Fan Y, Zeng Y, Li W, Lin F, Li S, Chen X, Pan P, medical team from Xiangya Hospital to support Hubei C (2020) Association of diabetes mellitus with disease severity and prognosis in COVID-19: a retrospective cohort study. Diabetes Res Clin Pract 165:108227. https://doi.org/10.1016/j.diabres.2020.108227

28. Zhao M, Wang M, Zhang J, Gu J, Zhang P, Xu Y, Ye J, Wang Z, Ye D, Pan W, Shen B, He H, Liu M, Liu M, Luo Z, Li D, Liu J, Wan J (2020) Comparison of clinical characteristics and outcomes of patients with coronavirus disease 2019 at different ages. Aging 12(11):10070-10086. https://doi.org/10.18632/aging.103298

29. Huang I, Lim MA, Pranata R (2020) Diabetes mellitus is associated with increased mortality and severity of disease in COVID-19 pneumonia - a systematic review, meta-analysis, and meta-regression. Diabetes Metab Syndr 14(4):395-403. https://doi.org/10. 1016/j.dsx.2020.04.018

30. Kumar A, Arora A, Sharma P, Anikhindi SA, Bansal N, Singla V, Khare S, Srivastava A (2020) Is diabetes mellitus associated with mortality and severity of COVID-19? A meta-analysis. Diabetes Metab Syndr 14(4):535-545. https://doi.org/10.1016/j.dsx.2020. 04.044

31. Mantovani A, Byrne CD, Zheng MH, Targher G (2020) Diabetes as a risk factor for greater COVID-19 severity and in-hospital death: a meta-analysis of observational studies. Nutr Metab Cardiovasc Dis. https://doi.org/10.1016/j.numecd.2020.05.014

32. Palaiodimos L, Chamorro-Pareja N, Karamanis D, Li W, Zavras PD, Mathias P, Kokkinidis DG (2020) Diabetes is associated with increased risk for in-hospital mortality in patients with COVID-19: a systematic review and meta-analysis comprising 18,506 patients. medRxiv. https://doi.org/10.1101/2020.05.26.20113811

33. Wu ZH, Tang Y, Cheng Q (2020) Diabetes increases the mortality of patients with COVID-19: a meta-analysis. Acta Diabetol. https:// doi.org/10.1007/s00592-020-01546-0

Publisher's note Springer Nature remains neutral with regard to jurisdictional claims in published maps and institutional affiliations. 